Original Research Paper

\title{
Identification of Retrofits Needed in Old Office Buildings to Achieve Thermal Comfort
}

\author{
Chipozya Tembo Silungwe, Josephine Mutwale Ziko and Edward Jims Sakala \\ Department of Construction Economics and Management, Copperbelt University, Kitwe, Zambia
}

\author{
Article history \\ Received: 23-08-2019 \\ Revised: 07-09-2019 \\ Accepted: 13-09-2019 \\ Corresponding Author: \\ Chipozya Tembo Silungwe \\ Department of Construction \\ Economics and Management, \\ Copperbelt University, Kitwe, \\ Zambia \\ Email: chipozya@yahoo.co.uk
}

\begin{abstract}
Building designs normally are made to offer a given level of comfort to occupants without any mechanical intervention. However, with the advent of global warming temperatures globally have been seen to rise making the occupants of most buildings uncomfortable. The immediate solution has been to add mechanical ventilation, which comes at an added cost of installation and running a building. A case study of old office blocks was used to determine the natural aspects of ventilation that can be utilized on existing old buildings to improve thermal comfort of the occupants after establishing the discomfort. The findings indicate that most office occupants have discomfort due to poor ventilation. This can be minimized with the use of high solar reflectivity roofing, appropriately colored walls, skylights, increased number of air vents and wide windows which are appropriately positioned.
\end{abstract}

Keywords: Natural Ventilation, Offices, Thermal Comfort, Zambia

\section{Introduction}

Climate change mainly in the form of global warming has resulted in most buildings not being comfortable thermally when used in their original design hence the need for adaptation. Adaptation should be focused on institutional (hostel, health, education, social/cultural) and commercial (hotel, retail, office, administration) buildings rather than usually short-lived industrial types of buildings (Bengtsson et al., 2007). It is inevitable that structures age and outgrow their original functions. With changes in technology and lifestyle, construction and design are constantly updated to meet modern demands and older structures are left in the wake of change (Clark, 2008). The planet is experiencing climate change with an increase in temperature being experienced in most places making thermal comfort for the occupants more important than ever. Retrofitting an existing building can oftentimes be more effective than building a new facility to attain thermal comfort for occupants. Since buildings consume a significant amount of energy (40 percent of the nation's total U.S. energy consumption), particularly for heating and cooling (32 percent) and because existing buildings comprise the largest segment of the built environment, it is important to initiate energy conservation retrofits to reduce energy consumption and the cost of heating, cooling and lighting buildings while promoting thermal comfort for occupants in the final analysis. This study focused on how old buildings could be retrofitted using natural means or by design to promote thermal comfort for occupants. The study sought:

- To identify factors contributing to thermal discomfort experienced by occupants

- To identify the nature and impact of the discomfort experienced by office occupants.

- To identify the preference measures to be implemented to promote natural thermal comfort

The organization of the paper in the next section outlines briefly the literature relevant to the study, the methodology that was used is given in the preceding section, then findings are presented and discussed. Finally a conclusion and recommendations of the study are given.

\section{Literature Review}

\section{Old Buildings}

Buildings are thought of as being very permanent structures. After all, most cities are filled with buildings that are hundreds of years old and in some cases, much older and just like everything else they depreciate over time. They have life cycles and they need to be regularly maintained and periodically renovated in order for them to survive. Although there is no standard definition for "old buildings", Bengtsson et al. (2007) states that "a large number of structures constructed around the 1970s 
are in need for maintenance. Old buildings are characterized by old ventilation systems, cracks, wear and tear and in need of renovations and maintenance. While new builds on the other hand tend to be energy efficient and as a result provide better thermal comfort to occupants. Many of the old buildings were created at a time when environmental standards were much lower and little or no consideration was given to sustainability. As a result, there are now many opportunities to retrofit existing buildings with sustainability-enhancing technology, delivering efficiency benefits for owners and tenants alike (Lendlease, 2017) and improve the thermal comfort for the occupants.

According to Bengtsson et al. (2007) the inventory of non-residential buildings suggest that climate change adaptation should be focused on institutional (hostel, health, education, social/cultural) and commercial (hotel, retail, office, administration) buildings rather than usually short lived industrial types of buildings. This criterion undoubtedly suits this case study which falls within the description of old buildings of commercial nature. When older buildings are compared to the new buildings, older buildings seem to hold qualities that have since been lost in modern designs such as historic qualities and as the management of older buildings remains one of the major challenges cities face as they try to make urban environments more sustainable, investing in an innovative solution is more important than ever (Lendlease, 2017).

Elefante (2007), emphasized the importance of dealing with the existing building stock. Quoting then-current statistics about the proportion of existing versus new, a point was made that no amount of new green construction can get us where we need to go if we ignore existing buildings: ideally "four out of every five existing buildings will be renovated over the next generation while two new buildings are added". This is because it may sometimes be more economical to renovate than to demolish and rebuild. Therefore, it is often during renovations that retrofits are introduced to improve thermal comfort, modernize and thereby making old buildings more energy efficient.

\section{Retrofitting and Thermal Comfort}

Retrofitting refers to the addition of new technology or features to older systems, the improving of existing buildings with energy efficiency equipment. Whilst the National Refurbishment Centre (2012) defines the term Retrofitting as "the installation of individual or multiple energy efficiency measures to an existing building". An energy efficiency measure is any technology that improves the energy performance of the building, such as loft insulation, advanced heating controls and renewable energy generation technologies. The later definition of retrofitting is adopted for this study as the focus is to make existing buildings more energy efficient with the occupant in mind.
Thermal comfort is the condition of mind which expresses satisfaction with the thermal environment (Lim, 2012). From the aforementioned thermal comfort is difficult to define because a range of environmental and personal factors need to be taken into account when deciding on the temperatures and ventilation rates that make individuals feel comfortable. The best that can be realistically achieved in any situation is an environment, which satisfies the majority of people.

Climate change, which is both an increase in long-term average temperatures as well as an increase in climate variability, is due to an increased concentration of greenhouse gases in the earth's atmosphere has a lot to do with thermal comfort. As documented in the fourth assessment report of the IPCC (2014), the emissions of greenhouse gases have increased by $78 \%$ from 1970 to 2011, due to human activities. The increased greenhouse gas emissions have led to an increase in the greenhouse gas concentration in the earth's atmosphere, which traps some of the sun's heat. The well-observed impacts of this increased greenhouse gas concentration is an increase in the earth's global average surface temperature, increase in sea levels and last but not least the melting of the Northern Hemisphere's snow cover (IPCC, 2014).

Warming of the urban environment in summer is a particular issue of concern for human health, due to the risk of excess heat stress. Climate change is projected to increase summer day and night-time temperatures and will also intensify the urban heat island effect in cities. Adapting cities to climate change is therefore a high priority for urban planners and designers (Cavan and Aylen, 2012).

In October 2016, the Zambia Meteorological Department (ZMD) (2016) reported the unusual maximum temperatures of 40 and $41^{\circ} \mathrm{C}$ in some parts of Zambia as compared to other times were the highest recorded temperatures in October has been $37^{\circ} \mathrm{C}$, with the lowest recorded temperatures at $9^{\circ} \mathrm{C}$ (George, 2017). These hot-temperature regimes were associated with the hot-dry and hot-wet seasons Zambia recorded its hottest temperatures in history, October 13 , when the mercury recorded $42.4^{\circ} \mathrm{C}\left(108.3^{\circ} \mathrm{F}\right)$ in Mfuwe. The previous record was $42.3^{\circ} \mathrm{C}(108.3 \mathrm{~F})$ set on November 17, 2005. Throughout the month of October daytime temperatures will generally reach highs of around $32^{\circ} \mathrm{C}\left(90^{\circ} \mathrm{F}\right)$, at night the average minimum temperatures drops down to $17^{\circ} \mathrm{C}\left(63^{\circ} \mathrm{F}\right)$ (Ibid).

General comfortable conditions for people working indoors performing light sedentary work are as follows, between 20 and 26 degrees Celsius, depending on the time of year and clothing worn, relative humidity 30-60\%, optimal air movement $0.1-.05 \mathrm{~m} / \mathrm{s}$ (naturally ventilated) and 0.1-0.2 m/s (air-conditioned) (Bjorn, 2017). When people are dissatisfied with their thermal environment, not only is it 
a potential health hazard, it also impacts on their ability to function effectively (CIOB, 2017). Human health is particularly sensitive to climate and weather patterns because many diseases in the tropics are associated with temperature and precipitation changes. One of the ways to achieve thermal comfort is through natural ventilation.

\section{Natural Ventilation}

Ventilation should be controllable by the occupants. Individual control of ventilation improves the user satisfaction. This means that individual means of controlling the thermal comfort should be provided. Operable windows provide one way to control ventilation and should be provided, particularly, if climatic conditions and location of building are favorable for natural ventilation (CIB, 2004). According to Hazim (2010) natural ventilation is where the airflow in a building is as a result of wind and buoyancy through openings or cracks within the building envelope. Zhai et al. (2015); Normura and Hiyama (2017) further posit that natural ventilation should be efficient enough to reduce building energy need and improve indoor air quality.

Natural ventilation efficiency and building thermal comfort are affected by both internal and external factors (Cai Feng and Wai Ling, 2010). Internal factors are majorly dependent on openings control setup and building designs and can be varied or engineered for the desired conditions (Wikipedia, 2017) while external factors include building orientation, location and prevailing weather conditions. These are usually natural and constrained. Some of the mechanisms used to control thermal comfort include the following listed below.

\section{Opening Controls}

Adoption of manual control of windows is to have the window opening and closure left to the occupants. Windows in this strategy are opened by the occupants this usually happens whether or not the outside temperature is above the inside temperature. Though considered the lowest cost option, a challenge in this strategy is that at times occupants neglect or forget to open and close the windows when the outdoor conditions vary in an unpredictable manner hence leading to thermal comfort problems (Window, 2012). Zhai et al. (2015) notes that for openings to be effective more than one is required. Further, the openings should be positioned in a way that minimizes obstructions if much air flow is needed and vice versa if not much air is needed. The occupants' neglect of either failing to close or open openings could be circumvented with automated opening systems which should be operated with a temperature control setting in mind to be effective.

\section{Automated Window Control}

In automated window control, an automatic window control device is installed on the window (s). This device has a temperature sensor set to a set point temperature that opens the windows when the inside temperature is higher than the outside temperature and closes the window when the inside temperature is lower than the outside temperature (Carrilho et al., 2003). Here windows can be opened to a variable width depending on the change in inside temperature. Of paramount importance in opening window opening systems are the desired window to wall ratios that are normally set by standards that normally required in building regulation.

\section{Window Wall Ratio (WWR)}

According to Marino et al. (2017), Window-to-Wall Ratio (WWR) also known as window area is considered as a very important parameter affecting the thermal performance of a building. WWR is usually measured as the percentage area determined by dividing the building's total glazed area by its exterior envelope wall area. Optimized window design is vital in achieving thermal comfort with no additional financial investment and a reduction on dependence on air conditioning coupled with reduction of discomfort periods are realized (Ibid).

\section{Lighting Control}

As a method of reducing internal loads generated from lights, electric lights can be controlled (Design Builder, 2010). Daylight luminance level in a zone depends on many factors, including sky conditions, sun position and location, size and glass transmittance of windows, window shades and reflectance of interior surfaces (Hazim, 2010). Lights should be properly positioned and selected to ensure that they do not interfere with the thermal comfort of occupants. Apart from the walls, the roofing system also plays a significant role in promoting thermal comfort.

\section{Roofing Sheet Type}

The excessive heat transferred through the roof is one of the main causes of thermal discomfort in warm humid/tropic climatic conditions, which prevail in the tropical zone. Therefore, the selection of the most appropriate roof orientation and materials will be important for desirable thermal performances of passive buildings (Jayasinghe et al., 2003).

\section{Thermal Insulation}

There are many different types of thermal insulation materials, e.g., loose fills, rock wool and boards. The materials acts as a barrier, which slows heat flow in the summer and heat loss in other seasons, but it is only effective where there is a temperature difference between the inside and outside of the building or between two areas inside a building (Todd and Cue, 2013). If a significant proportion of people are experiencing discomfort in a work area for a long period of time the causes of the discomfort should be investigated (Nigel et al., 2009) as 
thermal discomfort often times contributes to poor productivity. It is evident that the coating of external surfaces with cooling painting will contribute to the reduction of cooling demand. However, in locations with high solar radiation, the application of reflective coatings may counteract the performance of the building envelope during the cold season period, as the building may not take advantage of the excess insulation (Ibid).

\section{Wind}

Lechner (2015); Olgyay (1963) asserts that desirable air movements should be utilized for cooling in hot periods and as a relief from vapor pressure during times of high absolute humidity. Conversely, air movements should be blocked and avoided during the cold season as air movement affects body cooling (Ibid). Air movement, does not decrease temperature but causes a cooling sensation due to heat loss by convection and due to increased evaporation from the body. As velocity of air movement increases, the upper comfort limit is raised. However, this rise slows down as higher temperatures are reached. Wind therefore plays a significant role in promoting thermal comfort.

\section{Thermal Adaptive Categories}

There are basically three categories of thermal adaptation; these are physiological adaptation, psychological adaptation and behavioral adaptation (Susana, 2011). Others considerations that shape a persons for adaptation include culture, gender and thermal expectations. Therefore, thermal comfort is a controversial issue that becomes even more controversial when investigating thermal satisfaction in a group of people working in a common space, such as the occupants of an office building (Fanger 2001).

According to De dear and Brager (2001) the adaptation is based on the idea that outdoor climate influences indoor comfort because humans can adapt to different temperatures during different times of the year. The adaptive hypothesis predicts that contextual factors, such as having access to environmental controls and past thermal history can influence building occupant's thermal expectations and preferences.

Numerous researchers have conducted field studies worldwide in which the survey building occupants about their thermal comfort while taking simultaneous environmental measurements. Analyzing a database of results from 160 buildings revealed that occupants of naturally ventilated buildings accept and even prefer a wider range of temperatures than their counterparts in sealed, air-conditioned buildings because their preferred temperatures depends on outdoor conditions (ANSI/ANSHRAE 2013). These results were incorporated in the ASHRAE 55-2004 Standards as the adaptive comfort model (ANSI/ANSHRAE 2013).

\section{Methodology}

A case study approach is more appropriate when the researcher wants to understand an organization's phenomena within their real-life contexts (Stake, 2000; Yin, 2003). The case study for this research focused on the Copperbelt University specifically the School of the Built Environment and School of Business office blocks. The Copperbelt University is a public higher learning institution located in Kitwe (Copperbelt province), Zambia. It was established by the act of parliament in 1987 (Southern African Regional Universities Association, 2014). The University is ranked second in Zambia after the University of Zambia. The two schools under the university (case studies) have different office partitions and sizes. The reason for selecting the old (School of Built Environment SBE) and new building (School of Business SOB) is the nature of the study since its focus is on the retrofitting of old structures for thermal comfort adaptability, which has a parametric basis. The School of the built environment has 19 office spaces with a majority of naturally ventilated offices, while the school of business studies has 16 office spaces to be considered, which brings our total population to 35 offices. Judgmental sampling was used in sampling considering mainly orientation of offices.

Guidelines outlined in the ASHRAE 55 were used as guides in determining margins of human thermal comfort. ASHRAE states that thermal comfort inside buildings is achieved when indoor environmental conditions satisfy $80 \%$ of office occupants, owing to the fact that it is practically impossible to please all the occupants even some of the time. Literature has defined the meaning of common terms in thermal comfort. These have been broadly debated and defined in ASHRAE-55 2010 (ASHRAE, 2004) and ISO-7730 1995 (EN ISO, 1995), such as:

1. Thermal comfort: Condition of mind, which expresses satisfaction under certain thermal environments

2. Acceptable thermal environment: When at least $80 \%$ of the occupants would agree that the thermal environment is acceptable

3. Thermal sensation: A conscious feeling graded into seven categories: cold, cool, slightly cool, neutral, slightly warm, warm and hot

The main primary data collection tools were a two part survey questionnaire, an observation checklist and photographs. A total of 19 questionnaires for school of built environment and a total of 16 questionnaires for school of business were administered to the office occupants, bringing the total of questionnaires to 35 , with a success rate $95 \%$ returned, hence making the sample representative and the inference can be made from it valid for analysis and generalization to similar cases. Data were analyzed, mainly using frequencies and content analysis. 


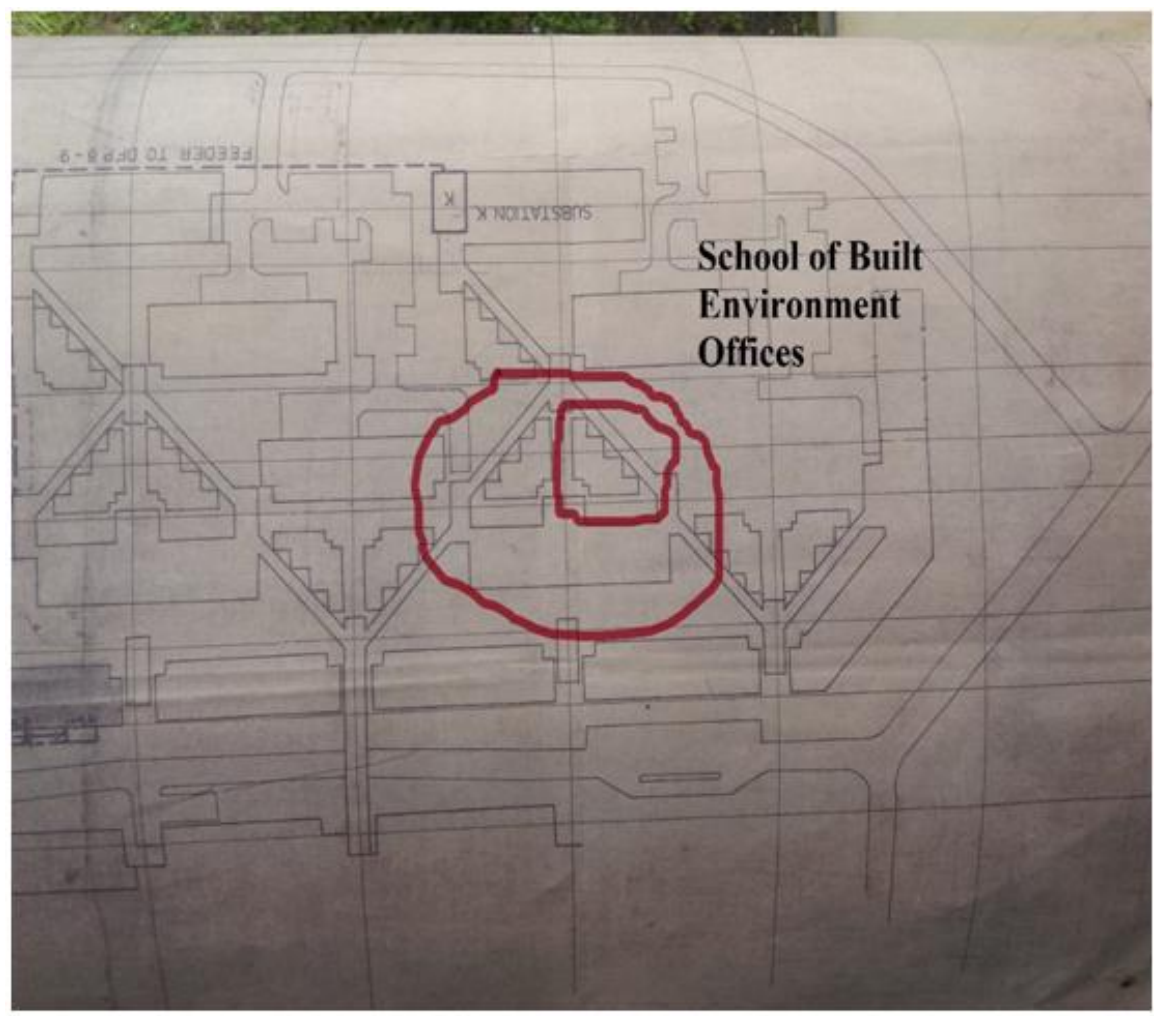

Fig. 1: Case a school of built environment

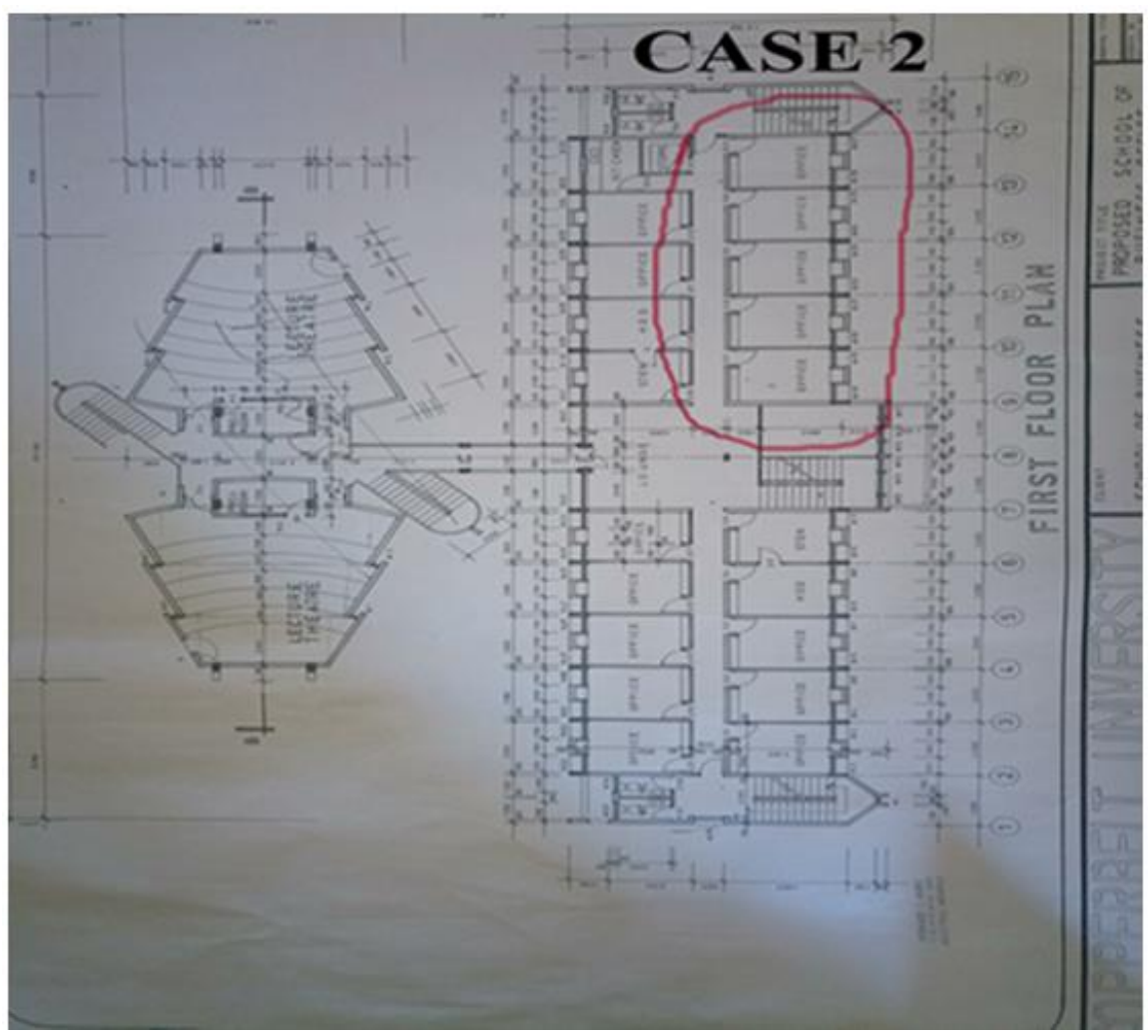

Fig. 2: Case b school of business 


\section{Characteristics of the Case Study}

The Copperbelt University offices were used as cases to determine the nature of the discomfort and the necessary solutions needed to promote thermal comfort. The offices comprised of two separate cases built at different times one in 1979 Case A (SBE) (Fig. 1) and the other in 2008 Case B (SOB) (Fig. 2). The School of the built environment, which has 19 office spaces with a majority of naturally ventilated offices, while the school of business studies has 16 office spaces to be considered on the ground floor, which brings our total population to 35 offices. Offices for SBE are single storey with asbestos roof with a pitch of no more than 22 degrees. The ceiling is particle board painted white with PVA paint. The walls are $200 \mathrm{~mm}$ concrete block-work covered in cement mortar plaster (roughcast external walls) and the windows are single glazed with $4 \mathrm{~mm}$ clear glass except for toilets. The school has two buildings the first building is tiled with ceramic tiles and building two has PVC tiles. The interior of both buildings is painted with white with PVA paint the exterior is finished in ruff cast for School of Built Environment (SBE) and School of Business (SOB). For the school of business, the office blocks are also single stored though some offices are located at the bottom of double storey buildings. The walls are $200 \mathrm{~mm}$ block wall and floor is terrazzo. The roofing is IT4 painted green with a particle board ceiling painted white.

\section{Results and Discussion}

\section{Response Rate}

A structured questionnaire was used to obtain data and the response rate for SBE was 17/19 Office representing $90 \%$ of the occupants while for the SOB all 16 office occupants responded representing 100\% response rate. Therefore, the validity of the office occupants thermal discomfort could be considered valid as the response rate was high as shown in Table 1.

\section{Temperature Changes for the Case Study}

The data from the Copperbelt university meteorological station, for the year 2016 and 2017, months of October showing the minimum and maximum temperatures fluctuations is illustrated below in Fig. 3 and 4 and analyzed.

To understand and assess the impact of climate change on the universities office occupants fully, it's important to first know the thermal comfort trends and the comfort zone temperatures for Kitwe or the Copperbelt University, using Humphrey's comfort equation. The relationship between the indoor thermal comfort and outdoor mean temperature presented by Humphrey's equations are used to define the ranges of the indoor thermal comfort for Kitwe for the
Naturally Ventilated Buildings (NVB). For naturally ventilated buildings: $T c=11.9+0.534 \mathrm{Tm}$, Where $T c$ is the comfort temperature and $\mathrm{Tm}$ is the mean outdoor temperature. A comfort zone within which temperatures are generally acceptable can be taken to extend some $2-3^{\circ} \mathrm{C}$ either side of this optimum temperature.

\section{Comfort Temperature Equation:}

$$
T c=11.9+0.534 T m
$$

where, $T c$ is comfort temperature, $T m$ is the monthly mean temperature which in this case is for October 2016 and October 2017.

Therefore:

$$
\begin{aligned}
& T c=11.9+0.534(16.12) \\
& T c=21^{\circ} \mathrm{C}
\end{aligned}
$$

This is the comfort zone, temperature for the Copperbelt University 2016.

So once we add the 2-3 on either sides this comes to $24^{\circ} \mathrm{C}$ and $18^{\circ} \mathrm{C}$ as the Comfort temperatures for 2018:

$$
T c=11.9+0.534(18.03)
$$

$T c=22^{\circ} \mathrm{C}$ (Comfort Temperature, October, 2017) $19^{\circ} \mathrm{C}$ and $25^{\circ} \mathrm{C}$, after removing -3 and adding +3 .

It can be seen that even after adding and subtracting the allowance the comfort temperatures are partially within the recommended range.

This is the comfort zone, temperatures for the Copperbelt University 2017. Findings indicate an increase of $1{ }^{\circ} \mathrm{C}$ in climate change between the year 2016 and 2017 and this is projected to increase the hot-season day and night-time temperatures even more as shown by literature, this will cause the urban heat effects to intensify with higher temperatures, henceforth adapting the two case studies to climate change is a high priority for the Copperbelt university, if such devastating effects of climate change on thermal comfort are to be eliminated.

As established from the equations, $21^{\circ} \mathrm{C}$ and $22^{\circ} \mathrm{C}$ is the preferred comfortable temperature for the Copperbelt University (Kitwe) for the years 2016 and 2017 respectively. Further analysis shows that from the year 2016 to 2017 there has been an increase in the comfort temperatures of $1{ }^{\circ} \mathrm{C}$ degree Celsius, this might not be a significant number but it's a very huge increase in terms of temperature increase and this clearly shows that the comfort levels for people are clearly decreasing with increase in comfort temperature levels. Further analysis shows that temperatures have been high on average as far as $41^{\circ} \mathrm{C}$ Celsius which is far more beyond the comfort temperatures of $21^{\circ} \mathrm{C}$ and $22^{\circ} \mathrm{C}$ degree Celsius. Should the temperatures increase beyond the comfort temperatures, this will result in thermal discomfort. 


\section{minimum and maximun temeratures for October 2016}

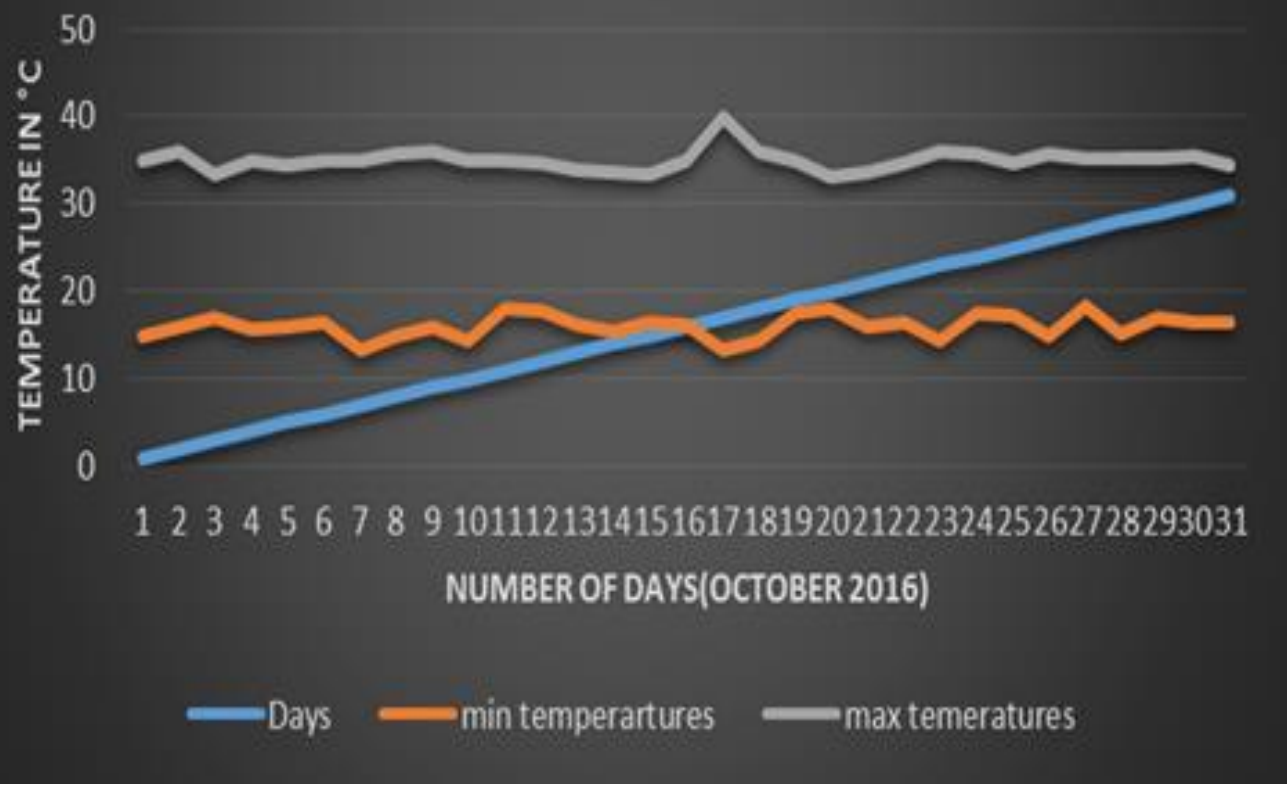

Fig. 3: Minimum and maximum temperature changes for October 2016

\section{minimum and maximun temeratures}

\section{for October 2017}

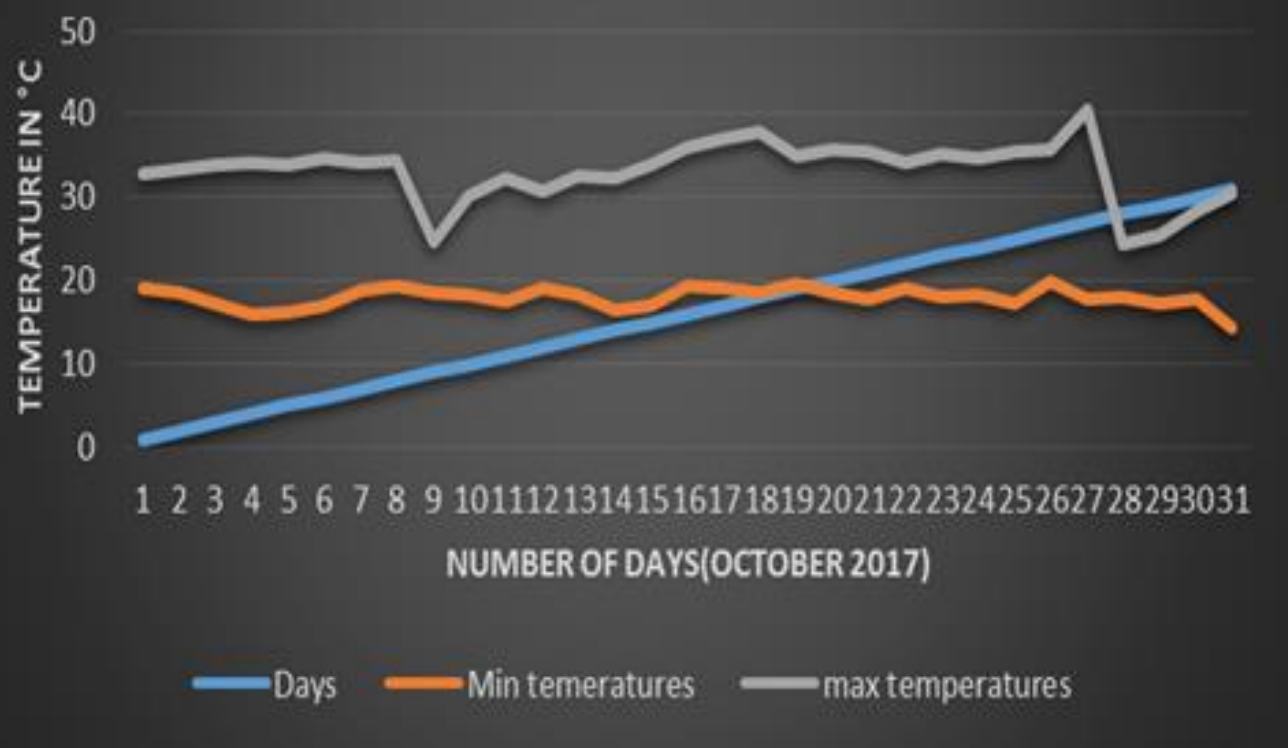

Fig. 4: Minimum and maximum temperature changes for October 2017 
Table 1: Response rate

\begin{tabular}{lllll}
\hline & & No. of questionnaires & \multicolumn{2}{c}{ No. of questionnaires } \\
Respondents & Sample size & Distributed & 17 & Response rate \\
\hline School of Built Environment (SBE) & 19 & 19 & 16 & $90 \%$ \\
School of Business (SB) & 16 & 16 & $\mathbf{3 3}$ & $100 \%$ \\
Total & $\mathbf{3 5}$ & $\mathbf{3 5}$ & $\mathbf{9 4 \%}$ \\
\hline
\end{tabular}

Air velocity, on the other hand, did not appear to significantly predict thermal comfort scores, as it was within the recommended range of 0.1 and $1.5 \mathrm{~m} / \mathrm{s}$. Previous thermal comfort research has shown that psychological variables can be even more important than environmental variables in predicting thermal comfort (De Dear and Brager, 2001). Given that air velocity is just one of the four physical environmental variables that could affect thermal comfort (Fanger, 2001) and that there might be other psychological factors that were influencing thermal comfort during the time of the survey, it is likely that the effects of air velocity might have been masked by these other variables.

According to Yeang (2006) air movement of $1 \mathrm{~m} / \mathrm{s}$ will reduce an air temperature of $30.25^{\circ} \mathrm{C}$ to an effective temperature of $27.25^{\circ} \mathrm{C}$. Ceiling fans, which uses a sixth of the amount of energy as air conditioning, would be a good strategy to supplement natural ventilation if the required rate of natural ventilation is too low (Yeang, 2006; 215; Heiselberg et al., 2002).

\section{Dissatisfaction of Occupants}

Slightly more than half $(56.92 \%)$ of the office occupants were clearly dissatisfied with the temperatures in their workspace. The high temperatures are as a result of increase of $1^{\circ} \mathrm{C}$ in temperatures between the year 2016 and 2017. This is further projected to increase during the hot-season day and night-time. This has caused the urban heat effects to intensify with higher temperatures leading to high discomfort levels. From the findings of this research the following impacts were identified from the increase in temperature:

- Increased occurrences of overheating in offices, due to the rapid increase in temperatures

- As outside temperatures become higher, the potential to provide cooling with comfort ventilation falls off, resulting in higher discomfort levels

- Higher levels of unproductivity, since the environment has become unconducive due to the thermal discomfort

- Higher demands for cooling (space) design mechanisms leading to high maintenance costs as more energy is being used for cooling

Majority of the office occupants $78.79 \%$ (SBE $57.58 \%$ and SOB $21.21 \%$ ) surveyed agreed that thermal discomfort disrupts their productivity whilst $15.15 \%$ did not agree that thermal discomfort disrupts their productivity. Notably the majority of the respondents that disagreed $(9.09 \%)$ and strongly disagreed $(6.06 \%)$ are those that occupy the Air-conditioned offices as they stressed the point that, they are able to adjust the airconditioner to suit their needs at a particular moment or rather throughout the year.

The major consequences as articulated by the office occupants was fatigue, dizziness, sweating, drowsy, headache, fan blowing hot air for those that use the fan for ventilation, gasping for air and sweating in the early hours of the day especially in the school of built environment. In the Air-conditioned Offices, the main cause of thermal discomfort was lighting as most demanded the increase of the window size (height and widening the windows). Other effects of thermal discomfort mentioned included Sickness and reduction in Self-esteem due to Body odor this was articulated by some office occupants.

The findings have further showed that $76.47 \%$ (13 out of 17) respondents from the School of Built environment identified too little air movements in the offices resulting from poor cross ventilation and this is supported by the by the fact $41.18 \%$ of the windows in the school of built environment are dysfunctional and on occasion there is no cross ventilation due to the design and surrounding buildings. On the contrary, the school of business has $100 \%$ functional windows and as a result less than half of the occupants $43.75 \%$ (7 out of 16 respondents) stated the presence of too little air movements and this explains the higher comfort levels by SOB office occupants. With these findings, this research has concluded that adapting old buildings at the institution will contribute to the thermal comfort of office occupants moreover Jomehzadeh et al. (2017) point out that global warming currently threatens mankind hence an emphasis on natural cooling which could also reduce energy consumption of buildings.

\section{Factors Contributing to Thermal Discomfort}

Thermal sensation levels are shown in Fig. 5 for both cases. Discomfort levels from the School of Built Environment can be attributed to many factors namely:

- Poor ventilation, due to blocked air-vents and lack of air-vents for some offices

- $58.82 \%$ dysfunctional windows while the school of business has $100 \%$ functional windows 
- Poor lighting in more than half of the offices $(56 \%)$ where lighting systems are dangling and so close to the office work station

- Poor window shading mechanism systems from offices in the school of built environment;

- Lack of sustainable design features of the building envelope e.g., trees and other buildings blocking ventilation

Discomfort levels in the school of business are attributed to increase in temperature and poor cross ventilation in a few cases and blocked air vents. Clearly both designs seem to need some improvements for enhancing thermal comfort as it has been argued that design plays a primary role in promoting performance compared to other features such as floor area (Normura and Hiyama (2017).

\section{Preferences for Promoting Thermal Comfort}

\section{School of Business Needs and Preferences}

School of Built Environment office occupants (Fig. 6) needs and preferences are blinds as indicated by 10 out of 17 respondents $(58.82 \%), 8$ out of 17 want their windows widened for a thermally comfortable working environment. There was an equal preference for air vents and window awnings of $41.18 \% 7$ out of 17 respondents
$(41.18 \%)$ and in like manner the need for skylights and aluminium doors was $29.41 \%$ (5 out of 17 respondents) and on the contrary, double glazed windows was the least preffered and needed mechanism with a score of $5.88 \%$ ( 1 out of 17 respondents), to mention but a few. Air-conditioning score of $88.24 \%$ was recorded, however it should be noted this research is centred on natural ventilation and air-conditioning was incorporated only to show comparisons and substantiate the results between the two case studies.

Similarly, as can be seen from the Fig. 7, the School of Business office occupants voted $62.5 \%$ (10 out of 16 respondents) in need of air-conditioning and followed by blinds which scored $56.25 \%$ (9 out of 16 respondents). This difference could be attributed to the fact that most people in the school of business have more supportive thermal comfort mechanisms such as blinds, proper curtains, operable windows and clear air vents, this can also be seen from Fig. 1.

A comparative analysis between the two schools clearly shows that the demands from the school of business are lower as opposed to the school of built environment. The school of built environment has few windows that open and close and most of them are in a very poor state and need immediate attention.

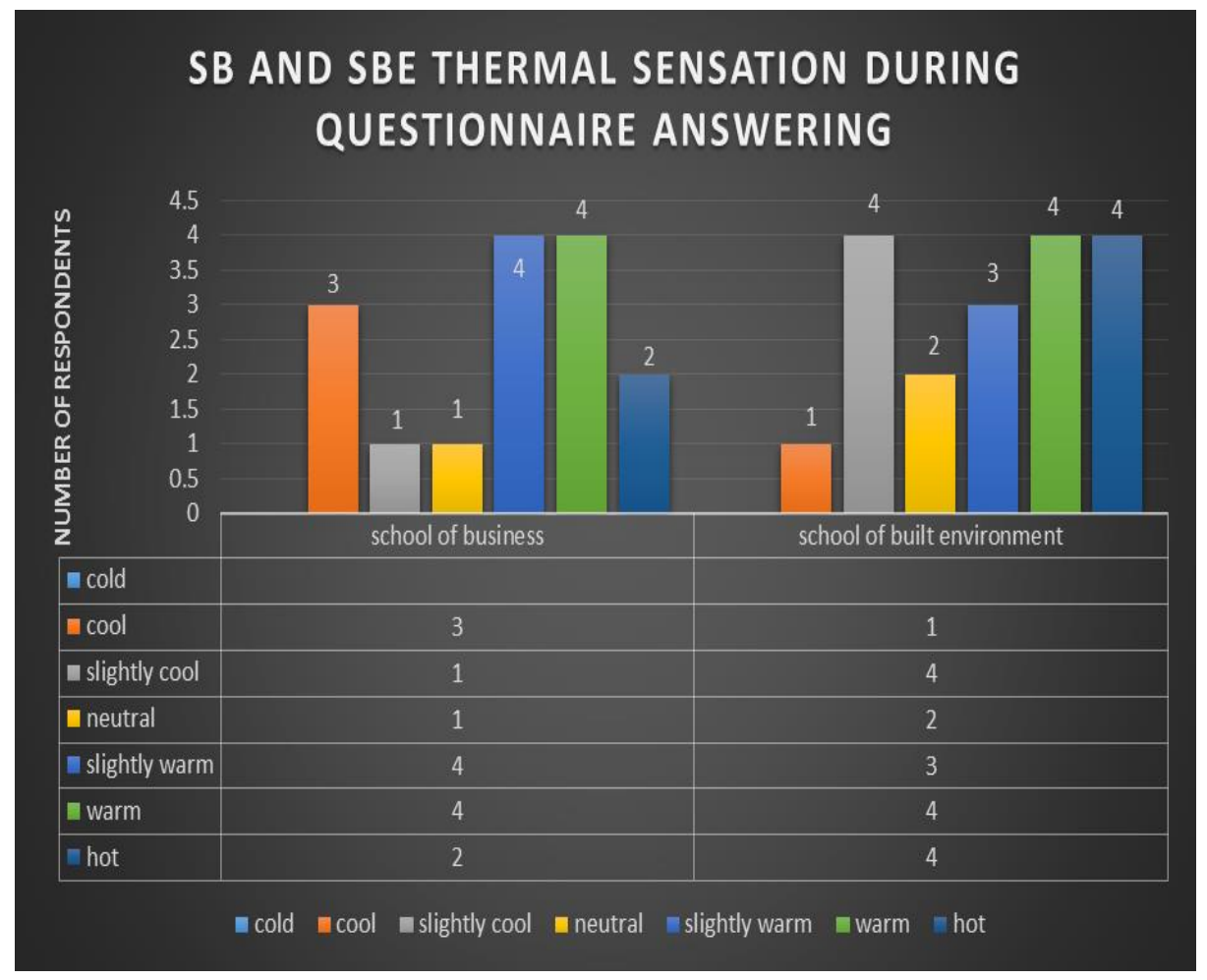

Fig. 5: Thermal sensation 


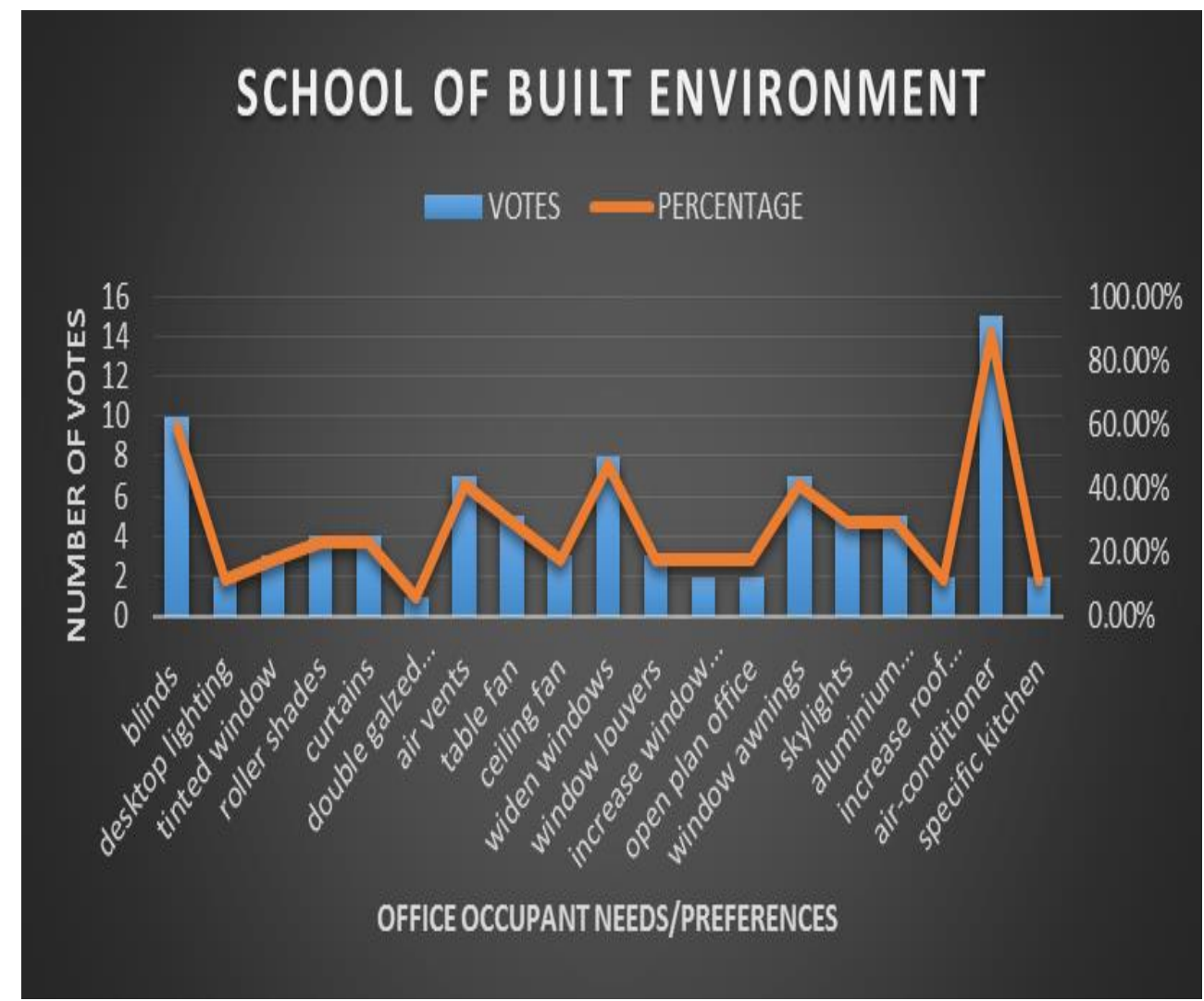

Fig. 6: SBE preferences

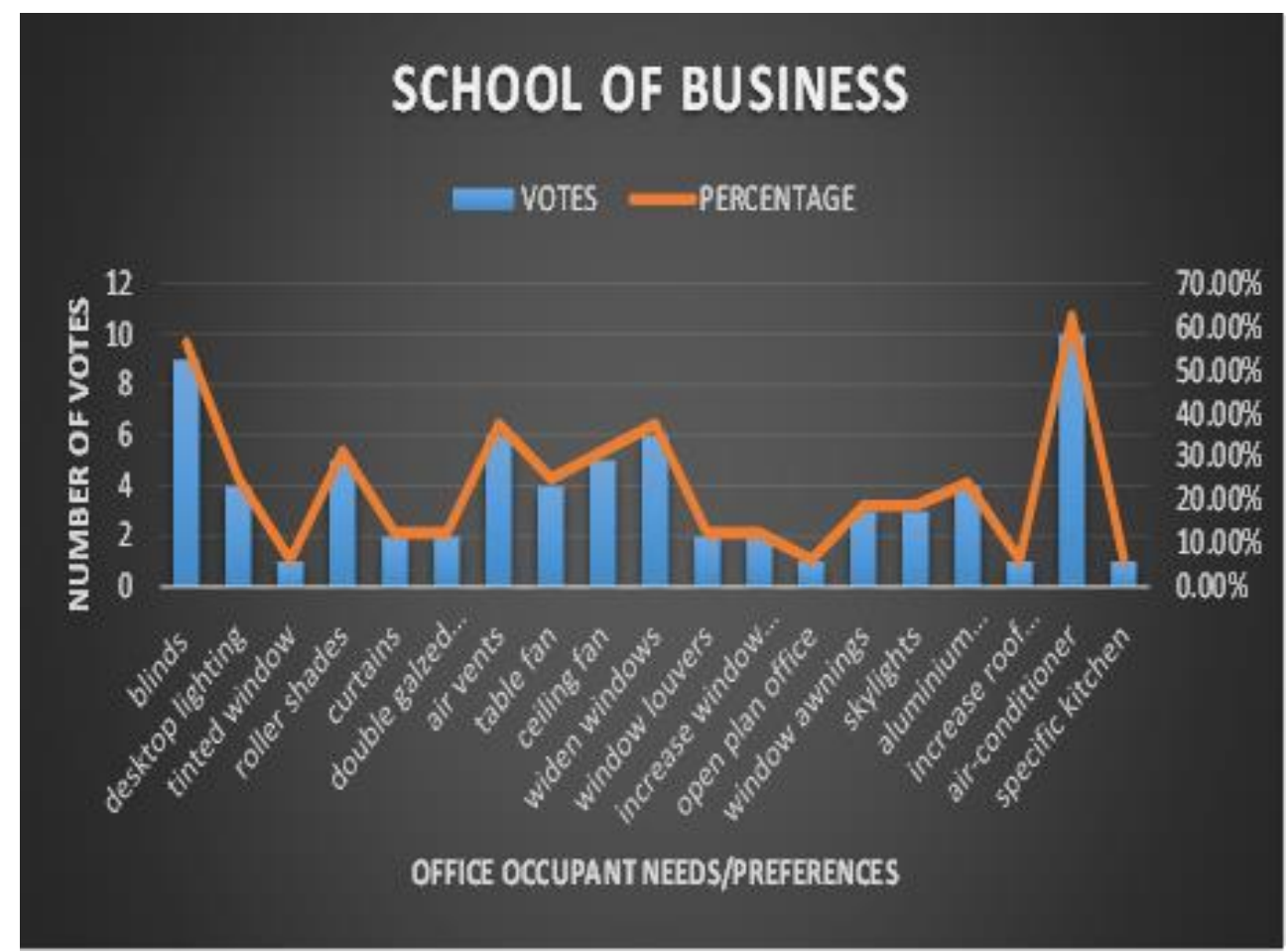

Fig. 7: Preferences for thermal comfort for SOB office occupants 
Table 2: Proposed improvements

\begin{tabular}{ll}
\hline Feature & Proposed improvement \\
\hline Wall (block work) & $\begin{array}{l}\text { Increase number of Air vents, paint external walls } \\
\text { white for a solar reflectivity of 50\%-90\% }\end{array}$ \\
Windows (pressed steel with single clear glazing) & $\begin{array}{l}\text { Blinds, Widen windows, roller shades and curtains, } \\
\text { Window awnings, functional windows }\end{array}$ \\
Doors (Flush for interior) & $\begin{array}{l}\text { Aluminum glass doors and windows } \\
\text { Install cooling tiles with high solar reflectivity index and } \\
\text { Roof (asbestos (SBE) and IT4 (SOB) } \\
\text { emittance, install high solar reflectivity roofing as opposed } \\
\text { to asbestos, Skylights such as or corrugated roof type }\end{array}$ \\
\hline
\end{tabular}

Such windows showed the presence of rust and are sticky and can hardly open. In light of all this,it is clearly noticeable that the school of built environment exhibit more needs and such magnitude of needs symbolises lack of such thermal comfort enhancers and mechanisms which further entails that the office occupants are not thermally satisfied.

\section{Recommendations for Promoting Thermal Comfort}

Table 2 summarizes the interventions that can be implemented to promote thermal comfort from the two cases studies as suggested by occupants.

\section{Conclusion}

At a global level rising temperatures have impacted the human habitant negatively due to climate change. The study has revealed that the occupants are experiencing thermal discomfort attributed mainly to poor ventilation resulting in poor productivity and increased cooling costs through the use of fans and other mechanical means. In view of this use of high solar reflectivity roofing, appropriately colored walls, skylights, increased number of air vents and wide windows that are appropriately positioned has been recommended. However, as this was a case study these recommendations can only be applied to buildings with similar design and climate conditions. Further research can be done on the cost implications of the proposed recommendations.

\section{Acknowledgement}

All the respondents for research from school of Built Environment and School of Business.

\section{Author's Contributions}

The following were the contributions made by the authors.

Chipozya Tembo Silungwe: Contributed to conceptualization, supervision and manuscript preparation.

Josephine Mutwale Ziko: Helped in the development of the literature.

Edward Jims Sakala: Responsible for conducting research and analysis.

\section{Ethics}

Authors should address any ethical issues that may arise after the publication of this manuscript.

\section{References}

ASHRAE 55, 2004. Thermal environmental conditions for human occupancy. Am. Society Heating, Refrigerating Air-conditioning Eng. Inc.

ANSI/ANSHRAE Standard 55, 2013. Thermal environmental conditions for human occupancy.

Bengtsson, J., R. Hargreave and I.C. Page, 2007. Assessment of the need to adapt buildings in New Zealand to the impact of climate change. Study report no. 179, BRANC publications.

Bjorn, E., 2017. Thermal comfort in the workplace: Guidance for employees. HSE.

Cai Feng, G.A.O. and L.E.E. Wai Ling, 2010. Influence of Window Types on Natural Ventilation of Residential Buildings in Hong Kong Department of Building Services Engineering. Hong Kong Polytechnic University, Hong Kong, China.

Carrilho, D.G.G., P.F. Linden and P. Haves, 2004. Design and testing of a control strategy for a large naturally ventilated office Building. Build. Services Eng. Res. Technol., 25: 223-239.

DOI: $10.1191 / 0143624404$ bt107oa

Cavan, G. and J. Aylen, 2012. The challenge of retrofitting Buildings to adapt to climate change: Case studies from Manchester. Ecocities Project, University Manchester, UK.

Clark, D., 2008. Adaptive reuse-a process of retrofitting old buildings for new uses-allows structures to retain their historic integrity while meeting the needs of modern occupants.

CIB, 2004. Performance Criteria of Buildings for Health and Comfort. CIB number 292.

CIOB, 2017. The state of well-being in the construction industry. 2017 Report edited by Keith S. Cattell Paul A. Bowen Sir Cary L. Cooper, CBE Peter J. Edwards, ISBN 9781527217904

De Dear, R.J. and G.S. Brager, 2001. 'Developing an adaptive model of thermal comfort and preference. ASHRAE Trans., 104: 145-67. 
Design Builder, 2012. Design Builder Loads Calculation Compliance ASHRAE183_v5.pdf http://www.designbuilder.co.uk/, Accessed on 15 th/10/18 at 12:50 Hours

Elefante, C., 2012. The Greenest Building Is... one that is already built. J. Natural Trust Historic Preservation. 27: 62-72.

EN ISO, 1995. International standard 7730: Moderate thermal environments-determination of the PMV and PPD indices and specification of the conditions for thermal comfort. Brussels: European Committee for Standardization.

Fanger, P.O., 2001. Human requirements in future airconditioned environments exigences humaines dans les environnements climatisés futurs. Int. J. Refrigerat., 24: 148-153.

DOI: $10.1016 / \mathrm{S} 0140-7007(00) 00011-6$

George, K., 2017. Assessing the environmental and socioeconomic risk factors of climate vulnerability in lowincome settlements of Kitwe City in Zambia.

Hazim, 2010. Basic concepts for natural ventilation of buildings. Technologies Sustainable Built Environments Centre University of Reading, UK.

Heiselberg, P., E. Bjørn and P.V. Nielsen, 2002. Impact of open windows on room air flow and thermal comfort. Int. J. Ventilation, 1: 91-100.

DOI: $10.1080 / 14733315.2002 .11683625$

IPCC, 2014. Climate Change 2014; Fourth Assessment Report, Intergovernmental Panel on Climate Change, Geneva, Switzerland.

Jayasinghe, M.T.R., R.A. Attalage and A.I. Jayawardena, 2003. Roof orientation, roofing materials and roof surface colour: Their influence on indoor thermal comfort in warm humid climates. Energy Sustainable Dev., 7: 16-27.

DOI: 10.1016/S0973-0826(08)60345-2

Jomehzadeh, F., N. Payam, C.K. John, Y.M. Badruddin Mohn and Z. AhmadSheikh et al., 2017. A review on Windcatcher for passive cooling and natural ventilation in Buildings, part 1: Indoor air quality and thermal comfort assessment. Renewable Sustainable Energy Rev., 70: 736-756.

DOI: 10.1016/j.rser.2016.11.254
Lechner, N., 2015. Heating, Cooling and Lighting: Sustainable Design Methods for Architects. 1st Edn., Wiley, New Jersey.

Lendlease, 2017. Annual report. Lendlease Corporation Limited ABN 32000226228 Incorporated in NSW Australia.

Lim, C.L., 2012. Thermal comfort guidelines and policy Pg. 1 and 2.

Marino, C., A. Nucara and M. Pietrafesa, 2017. Does window-to-wall ratio have a significant effect on the energy consumption of buildings? A parametric analysis in Italian climate conditions. J. Build. Eng., 13: 169-183. DOI: 10.1016/j.jobe.2017.08.001

National Refurbishment Centre, 2012. Refurbishing the Nation: Gathering the Evidence.

Nigel, A.S.T., C. Joanne and A.T. Elizabeth, 2009. Thermal comfort Guidelines University of Wollongong Australia.

Normura, M. and K. Hiyama, 2017. A Review: Natural ventilation performance of office buildings in Japan. Renewable Sustainable Energy Rev., 74: 746-754.

Olgyay, V., 1963. Design with climate, bioclimatic approach and architectural regionalism. Princeton (NJ), Princeton Press.

Stake, R., 2000. The art of case research. CA, thousand Oaks: Sage publications.

Susana G.S., 2011. Thermal Comfort with Radiant Walls. Salt Tower Residence.

Todd and Cue, 2013. Controlling workplace temperatures and assessing thermal comfort. HSE.

Wikipedia, 2017. Thermal comfort in Buildings.

Window, M., 2012. Fine control and natural ventilation.

Yeang, K., 2006. Eco-design, a manual for ecological design. Wiley-Academy, London.

Yin, R., 2003. Case Study Research: Design and Method. 3rd Edn., Sage.

Zambia meteorological Department, 2016. Weather database accessed on 20 December 2018 from www.zmd.gov.zm

Zhai, Z., E.M. Mankibi and A. Zoubir, 2015. Review of Natural ventilation models. Energy Proc., 78: 2700-2705. DOI: 10.1016/j.egypro.2015.11.355 